\title{
Evaluation of Nurses' Perceptions on Cardiopulmonary Resuscitation (CPR) Education
}

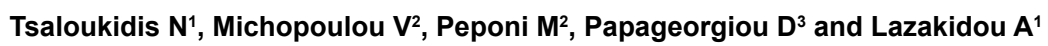

${ }^{1}$ Department of Economics, Digital Health Applications and Health Economics Laboratory, University of Peloponnese, Tripolis, Greece

${ }^{2}$ Department of Nursing, University of Peloponnese, Sparti, Greece

${ }^{3}$ Department of Nursing, School of Health and Welfare Professions, Technological Educational of Athens, Greece

\begin{abstract}
Background: One of the most common causes of death worldwide is sudden cardiac arrest. Nowadays, there is plethora of educational programs introducing basic life support skills among medical, paramedical stuff but also civilians. With the increasing use of computer technology, e-learning gains ground the recent years in several areas including medicine.
\end{abstract}

Purpose: An opinion research was conducted, about whether e-learning classes of CPR, conventional classroom learning or a mixed pattern are preferable among nurses.

Methods: Our study was conducted between August 2014 and April 2015 using an electronic survey uploaded in the official page of the National Regulatory Body of Nurses. In total 108 questionnaires were enrolled in the study after authenticity filtering.

Results: $70 \%$ of the responders believe that average tolerable educational cost for a BLS course is about or less of $25 € .96 .6 \%$ of the participants had CPR training before and a $90.8 \%$ desired to take further education or be retrained. $96.3 \%$ would apply CPR if needed with $67.9 \%$ not to quail from the risk of legal penalties. $84.4 \%$ had a certified knowledge of computers. Among e-learning, traditional classroom sessions and a combination of methods, $7.3 \%$ chose e-learning, $26.6 \%$ and $65.1 \%$ respectively classroom training or a combination of methods.

Conclusion: Nurses prefer to be trained by a combination of methods or else beginning to trust e-learning. The majority would offer a minimum amount of money for education. Encouraging, most of the participants have the intention to apply CPR if needed, despite the possibility for legal consequences.

Keywords: E-learning; CPR; Traditional classroom; Heart

\section{Introduction}

One of the most common causes of death worldwide is sudden cardiac arrest [1]. Including Europe, United States and Canada, each year 350,000-700,000 people are affected [2]. In US, approximately 350,000 people annually experience an out-of-hospital cardiac arrest, with mortality $92 \%$ and according to American Heart Association, $88 \%$ of them occur at home [3]. It is well known that expeditious application of cardiopulmonary resuscitation is of major importance [4]. Every time-delay after that has been accused for survival rates fall, with decrease $8-10 \%$ for every minute to pass [5]. As a matter of fact, these situations strongly create the need for trained layman rescuers and a coordinated community response [6].

Since recently, traditional resuscitation training that is classroombased was the only way to gain basic resuscitation skills [7]. As for running a traditional resuscitation training program, there are basic problems to be solved. Apart from the equipment and teacher'sinstructors' physical appearance, there have to be basic domestic facilities and planning of classroom working hours [8]. There is a fact that trainees' who work rotation shifts have to deal with a great challenge in order to attend such courses, not to mention money and time burden [9]. In general, civilian's access to resuscitation classroom learning training programs most of the times seems to be hard in terms of participation and the cost often burden themselves [10]. On the other hand, medical and paramedical staff, despite better access to training programs, sometimes shows poorer efficiency than expected in handling a cardiac arrest incidence, in or out of hospital, mostly due to lack of training, retraining or clinical experience [11-14]. For all these reasons, even health professionals but also volunteers show poor knowledge and experience in providing Basic Life Support, fact that created the need for introducing innovations in BLS training programs.

Nowadays, information technology (IT) has penetrated in every aspect of our lives, including science and medicine, providing the opportunity for time- and cost-effective training solutions [15]. As for resuscitation training, there is plethora of educational programs introducing basic life support skills, not only among medical and paramedical stuff but also civilians, even students. However, there is a controversy existing as for if civilians' training is effective at last, fact under discussion since smattering, poor retention of skills, lack of team coordination and not appliance when needed due to fear for legal implications are possible complications [16-18]. On the other hand, e-learning approach is not only compatible but also strongly suggested by resent international guidelines stating that core resuscitation knowledge might be gained by interactive media $[19,20]$. Among this alternative way of resuscitation training, in the game there is multiplayer virtual world (MVW) technology with avatars, serious

${ }^{*}$ Corresponding author: Tsaloukidis N, Digital Health Applications and Health Economics Laboratory, Department of Economics, University of Peloponnese, Tripolis, Greece, Tel: +00302108646239; E-mail: tsaloukidisn@gmail.com

Received January 03, 2016; Accepted February 13, 2017; Published February 15,2017

Citation: Tsaloukidis N, Michopoulou V, Peponi M, Papageorgiou D, Lazakidou A (2017) Evaluation of Nurses' Perceptions on Cardiopulmonary Resuscitation (CPR) Education. J Health Educ Res Dev 5: 209. doi: 10.4172/2380-5439.1000209

Copyright: (c) 2017 Tsaloukidis N, et al. This is an open-access article distributed under the terms of the Creative Commons Attribution License, which permits unrestricted use, distribution, and reproduction in any medium, provided the original author and source are credited. 
games, CD or DVD-based or instructor-led CPR education programs [21-24].

The aim of this study was to count nurses' beliefs about e-learning of CPR. Nurses' knowledge about e-learning methods, trust in them as long as beliefs about efficacy of these programs in comparison with face to face training was examined. The results of this study were associated with the samples' computer skills level, past CPR training, knowledge and occupational cardiac arrest experiences, demographic and socioeconomic data.

\section{Materials and Methods}

This survey was conducted between August 2014 and April 2015 using an e-questionnaire created using Google forms application. The questionnaire was uploaded in the official page of the National Regulatory Body of Nurses. The current study forms part of a wider survey dealing with beliefs about CPR e-learning in various employment branches, medical, paramedical and even civilians. The questionnaire consists of 31 questions, all of closed or semi-closedended type pertaining questions about nurses' training of CPR, time of training and awareness about education programs, computer skills and basic medical definitions, knowledge about e-learning methods as well as beliefs and trust in them, especially their efficacy versus traditional classroom training. At last, various demographic and socioeconomic data are included. In total, 108 questionnaires were enrolled after authenticity filtering based on the uniqueness of e-mail.

\section{Statistical analysis}

The analysis was performed with the statistical package SPSS 22.0. $\mathrm{P}$-values were based on two-sided tests and a significance level lower than 0.05 was adopted.

\section{Results and Discussion}

\section{Results}

The mean age of the participants was 36.21 years. $30.3 \%$ were men and $68.8 \%$ women. The sample consisted of nurses with the majority living in capital city's wide area (50.5\%), following by co-capital's wide area (7.3\%). $47.7 \%$ had received higher education, $43.1 \%$ had Master's degree and 7.3\% PhD diploma. As for the employment status, $69.4 \%$ were public servants, $13.8 \%$ private employees and $15.6 \%$ unemployed. $11.9 \%$ of our sample had no income, $4.6 \%$ earned below $500 € /$ month, $37.6 \%$ and $32.1 \%$ 500-1000 €/month and 1000-1500 €/month respectively and only $11.0 \%$ more than $1500 € /$ month (Figure 1 ).

About the average tolerable educational cost for a BLS course, $41.7 \%$ of the responders offered about $10-15 € /$ month, $27.8 \% 16-25 € /$ month and only $0.9 \%$ would spare more than $66-75 € /$ month (Figure 2 ).

The minimum tolerable cost for a BLS course was chosen by $38.5 \%$ of unemployed, $40.0 \%$ of employed with income below $500 € /$ month, $41.5 \%$ of whom earned between $500-1000 € /$ month, $45.7 \%$ with income $1000-1500 € /$ month and $41.5 \%$ of employees with income more than $1500 € /$ month. $96.3 \%$ had sometime taken training in Basic Cardiopulmonary Resuscitation. The last few years, there was a trend towards nurses' BLS training. For 2012, 2013 and 2014, the nurses had taken BLS training was $14.8 \%, 19.4 \%$ and $21.3 \%$ respectively and for $201511.1 \%$ with current data (Figure 3). $72.2 \%$ of the participants had been witnesses of a cardiac arrest incident at means of his occupation or not, while $67.6 \%$ had active participation in management of cardiac arrest incidents in general. Nevertheless, only $51.9 \%$ gave the right answer about cardiac arrest meaning, although all stated to be aware of it, with no noteworthy difference between public servants and private employees ( $54.7 \%$ and $53.3 \%$ respectively).

At computer skills part, $84.4 \%$ of the participants stated having certified knowledge of computers, $88.1 \%$ were operating computer at work and $99.1 \%$ had even some experience about handling. $90.8 \%$ were positive to take education or be retrained in BLS, whereas only $8.3 \%$ was not interested at all. As for training methods, among e-learning, traditional classroom sessions and a combination of methods, $7.3 \%$ chose e-learning, $26.6 \%$ and $65.1 \%$ respectively classroom training or a combination (Figure 4 ). At last, $96.3 \%$ would apply CPR if needed at a cardiac arrest victim, if properly trained and only $2.8 \%$ would deny help. Nevertheless, a possible legal implication would act as an inhibitory factor for $31.2 \%$, with percentage of $67.9 \%$ not to be influenced by that

\section{Discussion}

There are several research conducted the recent years testing the efficiency of e-learning methods but also the satisfaction of the attendants to these courses. In 2006, a study conducted in Seattle area high school students, aiming to compare the efficacy of classroom learning of $\mathrm{CPR}$, e-learning via interactive-computer training and a mixed pattern. The outcome was that classroom learning or a mixed pattern is more efficient in CPR training among high school students [25]. In a similar study among mental health care professionals, e-learners performed slightly better skills, although overall performance did not differ, concluding that e-learning education can be equivalent to classroom learning, but also useful as a preparation stage to traditional classroom course [26]. Among medical students, e-learning of pediatric resuscitation seems to offer improvement in both knowledge and competence, at least in the simulation environment [27]. Emergency department doctors and new graduate nurses of a pediatric hospital who participated in another survey, it seems that that e-learning improved both their knowledge and competence as for applying pediatric CPR in the stimulation environment [28]. In 2010, a study investigated the effectiveness of multiplayer virtual worlds using avatars in CPR training of medical students. The research showed promising results about resuscitation training efficacy but also the satisfaction of the participants was quite high [29]. In 2012, groups of pre-clinical medical students were pre-trained on CPR performance using serious game technology. Groups attended multiplayer virtual technology, seemed to be more efficient applying CPR in scenarios test [30]. In 2014, a study concerning emergency skills teaching, either by learning on video or face-to-face teaching, found no difference in efficacy of both training methods and also equal confidence to both training methods by the participants [31]. In 2015, the use of a platform (Moodle platform) as a pre-sessional phase prior to classroom phase of teaching advanced life support courses was studied. Both students and instructors that participated found e-learning pre-sessional phase very useful and helpful in fulfilling the main face-to-face course [32]. The same year, another study conducted among nurses, concerning a serious game (LISSA), created to complement CPR teaching or retrain knowledge. The outcome was that people trained by that serious game had significantly better learning acquisition versus classroom learning group [22].

There are many other studies among health care professionals trained in life support either by e-learning or by classroom learning courses, no difference was observed in both groups performance as for knowledge and skills or even higher scores were recorded in group of e-learning training, fact that strongly supports the e-learning option versus classroom learning. Moreover, computer-based training seems to positively impact teamwork and efficacy in patient care in simulated 
Citation: Tsaloukidis N, Michopoulou V, Peponi M, Papageorgiou D, Lazakidou A (2017) Evaluation of Nurses' Perceptions on Cardiopulmonary Resuscitation (CPR) Education. J Health Educ Res Dev 5: 209. doi: 10.4172/2380-5439.1000209

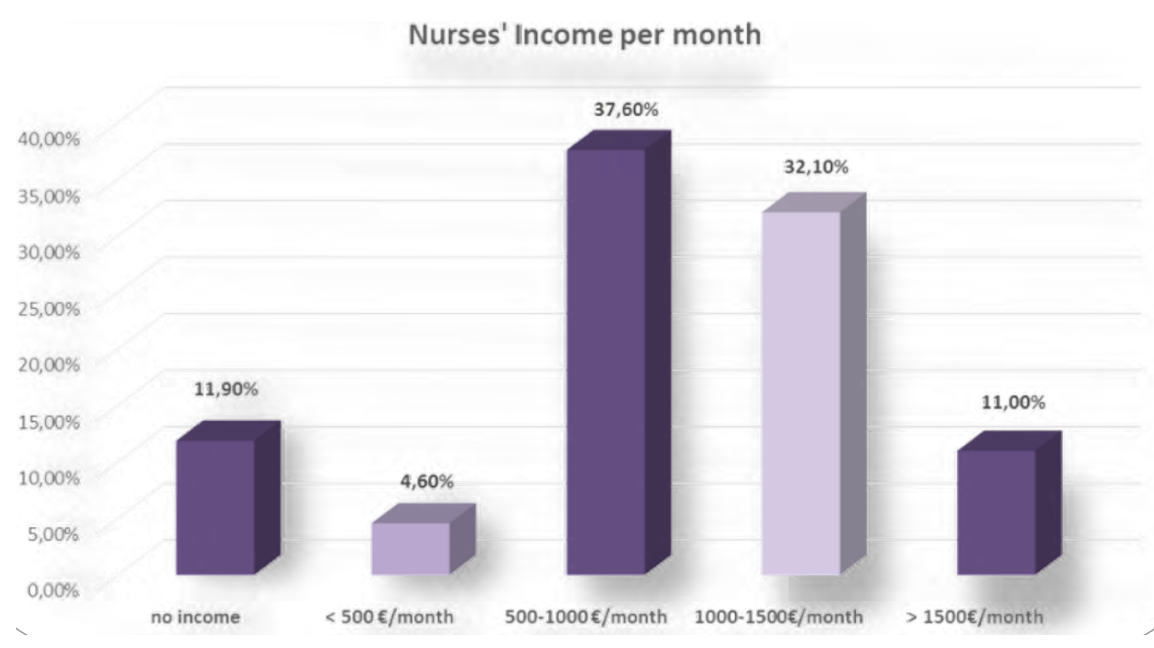

Figure 1: Nurses income per month.

\section{Average Affortable educational cost for a BLS course}

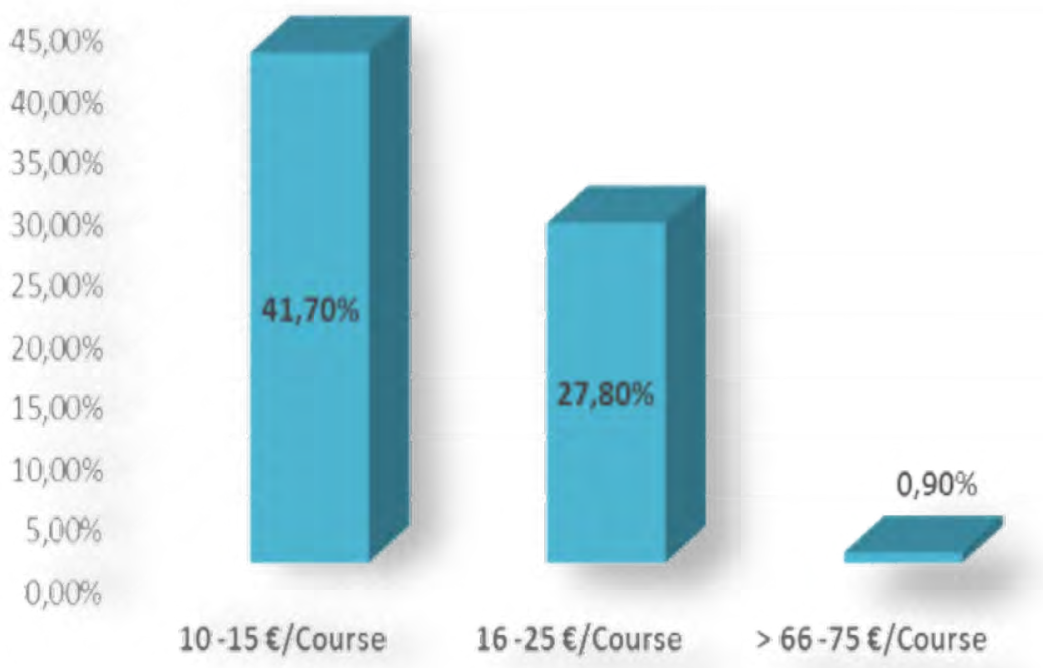

Figure 2: The average tolerable educational cost for a BLS course.

patient resuscitations [33-37]. Furthermore, electronic learning seems to offer the same technical and nontechnical skills in citizens training versus classic classroom learning, with all the drawbacks that civilians training exist [38-40]. Even the iPhone CPR application can significantly improve resuscitation performance among citizens [41].

Recent years, Greece is trying to introduce computer usage in terms of training and retraining human resources. However, by the end of 2010 , only $7.9 \%$ of businesses were using e-learning training as a method in order to educate their personnel. The above data proves that this manner of training is not well known; besides it is obvious that technology usage is almost catholic as well as computer usage in businesses with percentage of $90 \%$. In Greek territory's overall population, people using e-learning as a training method as about
$29.4 \%$, with this statistic to rise up even further in ages $16-25$ to $58.6 \%$. In Greek island region, for instance South Aegean islands, computer usage is about $70 \%$, percentage justified by the geographical remoteness of these areas. Generally, statistics are hopeful, since in Greece there is an augmentative account of people having internet access at home, with that percentage almost tripled from 2005 till today. Data from 2005 show that only $24.2 \%$ could surf web by their personal computer, with this percentage to be $61.5 \%$ in 2013 .

Another major theme discouraging people from applying CPR in Greece is lack of information about legal background of such actions. Greek legislation accommodates that there is no statutory liability against people having certified first-aid knowledge. However, there is a large amount of people, almost $1 / 3$ of our research respondents, 


\section{Nurses' BLS training per year}
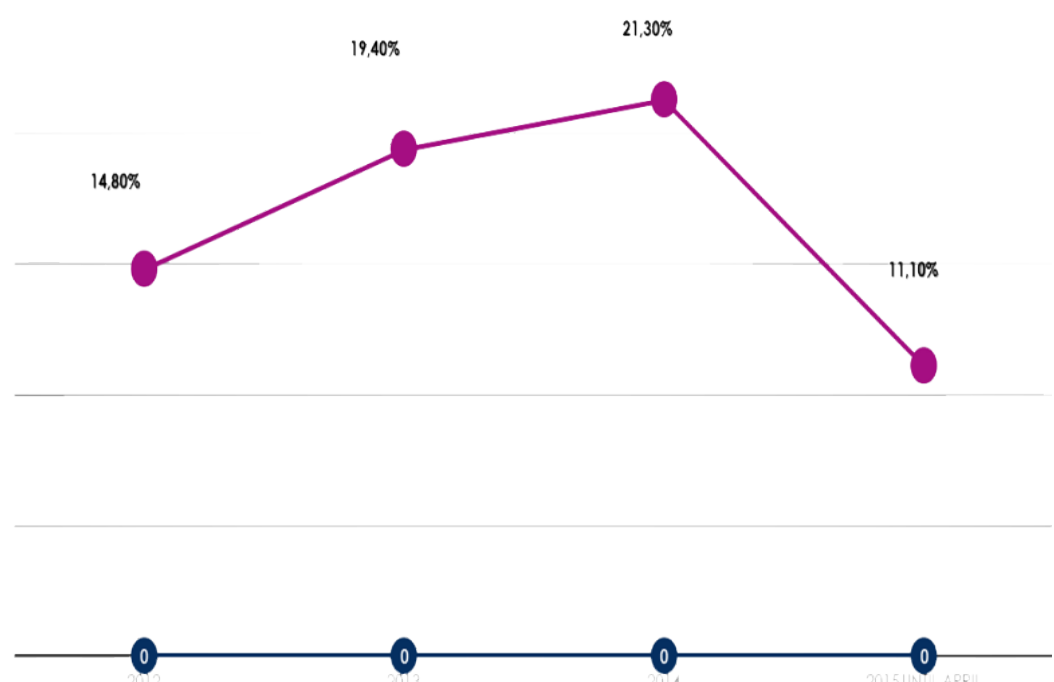

Figure 3: Nurses BLS Training per year.

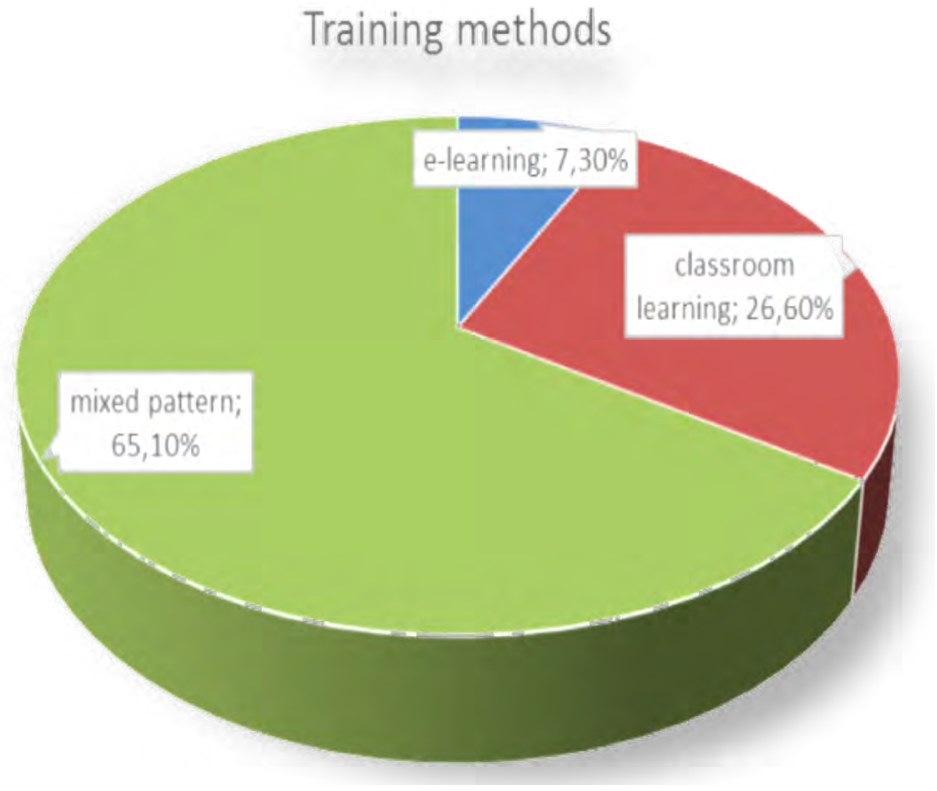

Figure 4: Training Methods.

who would not assist by using their skills and not apply CPR if needed. This would happen on the one hand due to fear, because of the sudden of the incidence, but also due to lack of knowledge for possible legal consequences as declared. There is a great omission concerning resuscitation training programs, not informing the participants about that the legal aspect of applying CPR, fact that is an imperative need. Sometimes, CPR legal background is even not mentioned at all. Other times, there is no formal reference and analysis of that subject, and at last no orientation that there is insurance against all liability in case of applying CPR, if certified.

Besides penalty background, Greek state, considering the importance of health professionals' BLS training, has established laws about the obligation of several health structures in educating their personnel. There are no official data about the efficacy of that legislation, even about the abidance of health structures. Nevertheless, from our data, a small amount of nurses seems to have taken education, 
encouraging though the fact that these numbers get bigger as the years' pass. Although, this fact is not clear if it derives from free enterprise or organized try from several structures.

According to the presented research, only a small amount of nurses prefer e-learning training versus traditional classroom learning as a training method. This data is in contrast with several facts. At first, the constrains that Greek territory creates due to difficulties in access to training programs such as long distances, bad road networks, island and outlying regions. Moreover, stress of modern life and especially for medical and paramedical stuff, rotated shifts and intensive rhythms of work in a critical specialization as this of health and need for several, long distance commutes per day, considering traffic congestion. At last, economic crisis the last years that had to be major motive for minimizing expenses versus classroom learning acquiring at least transportation expenses. All these facts would make it reasonable to have led to a higher preference of alternative, time and cost effective solutions for resuscitation training. Maybe the answer to that is lack of familiarization with different teaching methods, or distrust to them.

Although in Greece, nurses' education level in computer skills seems to be very high. However, this statistic may have led us to an error, since questionnaires were distributed only electronically, so nurses who were not familiar or had no access in computers were excluded from start. This restriction may also be responsible for greater increase of the statistic in e-learning preference in contrast with traditional learning. Moreover, only $51 \%$ of our sample gave the right definition for cardiac arrest meaning, despite responders' high education level as answered, including university studies and their mass statement for accurate knowledge of cardiac arrest definition. This may declare need for at least theoretical knowledge update, taken into account the fact that every 10 years there is a $7 \%$ knowledge loss according to bibliography.

It seems obvious that economic circumstances Greece deals with the past years have as a result, all nurses, despite their financial status, employed or unemployed, to consider that the lower cost is at least adequate for a BLS course. Although a secondary explanation, is lack of education about resuscitation meaning, theoretical and practical skills and of course the meaning of right application of CPR, not only as a practical skill but also updated with the most current data.

\section{Conclusion}

Nurses prefer to be trained by a combination of methods or else beginning to trust e-learning. There is an increasing will for BLS training or retraining. The level on computer skills is quite high, either on certified, or occupational, or even basic knowledge. The majority of the sample would offer the minimum amount of money for education, totally justified from the current socioeconomic status and the lack of public funding. However, the high educational level and the fact that most of the participants had some time deal with incidence of cardiac arrest, a great amount did not know the exact meaning of cardiac arrest, something that may be correlated with lack of retraining due to lack of state care. Encouraging, most of the participants have the intention to apply CPR if needed, despite the possibility for legal consequences.

\section{References}

1. AHA (2010) CPR \& Sudden Cardiac Arrest (SCA) Fact Sheet.

2. Gullo A, Ristagno G (2013) Resuscitation: Translational Research, Clinical Evidence, Education, Guidelines. Springer Science \& Business Media pp 83-91.

3. McNally B, Robb R, Mehta M, Vellano K, Valderrama AL (2011) Out-of-hospital cardiac arrest surveillance---Cardiac Arrest Registry to Enhance Survival (CARES), United States. 60: 1-19.
4. Straney LD, Bray JE, Beck B, Finn J, Bernard S, et al. (2015) Regions of high out-of-hospital cardiac arrest incidence and low bystander CPR rates in Victoria, Australia. PloS one 10: e0139776.

5. Weisfeldt ML, Becker LB (2002) Resuscitation after cardiac arrest: a 3-phase time-sensitive model. JAMA 288: 3035-3038.

6. Bachman JW (1984) Cardiac arrest in the community: How to improve survival rates. Post Med 76: 85-95.

7. Eisenburger $P$, Safar $P$ (1999) Life supporting first aid training of the publicreview and recommendations. Resuscitation 41: 3-18.

8. Norris EM, Lockey AS (2012) Human factors in resuscitation teaching Resuscitation 83: 423-427.

9. Passali C, Pantazopoulos I, Dontas I, Patsaki A, Barouxis D, et al. (2011) Evaluation of nurses' and doctors' knowledge of basic \& advanced life support resuscitation guidelines. Nurse Edu Pract 11: 365-369.

10. Capone PL, Lane JC, Kerr CS, Safar P (2000) Life supporting first aid (LSFA) teaching to Brazilians by television spots. Resuscitation 47: 259-265.

11. Hamilton R (2005) Nurses' knowledge and skill retention following cardiopulmonary resuscitation training: a review of the literature. J Adv Nurs 51: 288-297.

12. Myers LA, Russi CS, Schultz JL (2010) Paramedic Intercepts with Basic Life Support Ambulance Services in Rural Minnesota. Prehosp Disaster Med 25 159-163.

13. Rostgaard-Knudsen M, Dahl MK, Larsen K, Christensen T, Gade J (2008) Use of skills among ambulance crews assessed by ambulance on-line recordkeeping system. Ugeskrift for laeger 170: 247-251.

14. Guyette FX, Rittenberger JC, Platt T, Suffoletto B, Hostler D, et al. (2006) Feasibility of basic emergency medical technicians to perform selected advanced life support interventions. Prehosp Emerg Care 10: 518-521.

15. NHS Connecting for Health. (2006) National Programme for citation and use of an automatic external defibrillator to Health Online 69: 443.

16. Schmid KM, Mould-Millman NK, Hammes A, Kroehl M, García RQ, et al. (2016) Barriers and Facilitators to Community CPR Education in San José, Costa Rica. Prehosp Disaster Med pp1-7.

17. Swor R, Khan I, Domeier R, Honeycutt L, Chu K, et al. (2006) CPR Training and CPR Performance: Do CPR-trained Bystanders Perform CPR? Acad Emerg Med 13: 596-601.

18. Sasson C, Haukoos JS, Bond C, Rabe M, Colbert SH, et al. (2013) Barriers and facilitators to learning and performing cardiopulmonary resuscitation in neighbourhoods with low bystander cardiopulmonary resuscitation prevalence and high rates of cardiac arrest in Columbus, $\mathrm{OH}$. Circulation: Cardiovascular Quality and Outcomes 6: 550-558.

19. Baskett PJ, Nolan JP, Handley A, Soar J, Biarent D, et al. (2005) European Resuscitation Council Guidelines for Resuscitation 2005: Principles of training in resuscitation. Resuscitation 67: S181-S189.

20. Moule P, Albarran JW (2002) Automated external defibrillation as part BLS implications for education and practice. Resuscitation 54: 223-230.

21. Creutzfeldt J, Hedman L, Heinrichs L, Youngblood P, Felländer-Tsai L (2013) Cardiopulmonary resuscitation training in high school using avatars in virtual worlds: an international feasibility study. J Med Intern Res 15: e9.

22. Boada I, Rodriguez-Benitez A, Garcia-Gonzalez JM, Olivet J, Carreras V, et al (2015) Using a serious game to complement CPR instruction in a nurse faculty. Comput Method Progrms Biomed 122: 282-291.

23. Thorén AB, Axelsson AB, Herlitz J (2007) DVD-based or instructor-led CPR education-a comparison. Resuscitation 72: 333-334.

24. Perkins GD (2007) Simulation in resuscitation training. Resuscitation 73: 202-211.

25. Reder S, Cummings P, Quan L (2006) Comparison of three instructional methods for teaching cardiopulmonary resuscitation and use of an automatic external defibrillator to high school students. Resuscitation 69: 443-453.

26. Moule P, Albarran JW, Bessant E, Brownfield C, Pollock J (2008) A nonrandomized comparison of e-learning and classroom delivery of basic life support with automated external defibrillator use: A pilot study. Int J Nursing Pract 14: 427-434.

27. O'leary FM, Janson P (2010) Can e-learning improve medical students' 
Citation: Tsaloukidis N, Michopoulou V, Peponi M, Papageorgiou D, Lazakidou A (2017) Evaluation of Nurses' Perceptions on Cardiopulmonary Resuscitation (CPR) Education. J Health Educ Res Dev 5: 209. doi: 10.4172/2380-5439.1000209

knowledge and competence in paediatric cardiopulmonary resuscitation? A prospective before and after study. Emerg Med Aust 22: 324-329.

28. O'leary FM (2012) Paediatric resuscitation training: Is e-learning the answer? A before and after pilot study. J Paediatri Child Health 48: 529-533.

29. Creutzfeldt J, Hedman L, Medin C, Heinrichs WL, Felländer-Tsai L (2010) Exploring virtual worlds for scenario-based repeated team training of cardiopulmonary resuscitation in medical students. J Med Intern Res 12: e38.

30. Creutzfeldt J, Hedman L, Felländer-Tsai L (2012) Effects of pre-training using serious game technology on CPR performance-an exploratory quasiexperimental transfer study. Scandinav J Trauma Resuscit Emerg Med 20: 79.

31. Mohd Saiboon I, Jaafar MJ, Ahmad NS, Nasarudin NMA, Mohamad N et al. (2014) Emergency skills learning on video (ESLOV): A single-blinded randomized control trial of teaching common emergency skills using selfinstruction video (SIV) versus traditional face-to-face (FTF) methods. Medical teacher 36: 245-250.

32. Cordero TJ, Caballero OA (2014) The Moodle platform: A useful tool for training in life support. Analysis of satisfaction questionnaires from students and instructors of the semFYC advanced life support courses. Atencion primaria/ Sociedad Espanola de Medicina de Familia y Comunitaria 47: 376-384.

33. Khanal P, Vankipuram A, Ashby A, Vankipuram M, Gupta A, et al. (2014) Collaborative virtual reality based advanced cardiac life support training simulator using virtual reality principles. J Biomed Informa 51: 49-59.

34. Mardegan KJ, Schofield MJ, Murphy GC (2015) Comparison of an interactive CD-based and traditional instructor-led Basic Life Support skills training for nurses. Aust Critic Care 28: 160-167.
35. Krogh LQ, Bjørnshave K, Vestergaard LD, Sharma MB, Rasmussen SE, et al (2015) E-learning in pediatric basic life support: A randomized controlled noninferiority study. Resuscitation 90: 7-12.

36. Einspruch EL, Lembach J, Lynch B, Lee W, Harper R, et al. (2011) Basic life support instructor training: Comparison of instructor-led and self-guided training. J Nurs Profess Dev 27: E4-E9.

37. Fernandez R, Pearce M, Grand JA, Rench TA, Jones KA, et al. (2013) Evaluation of a computer-based educational intervention to improve medical teamwork and performance during simulated patient resuscitations. Critic Care Med 41: 2551-2562.

38. Hards A, Davies S, Salman A, Erik-Soussi M, Balki M (2012) Management of simulated maternal cardiac arrest by residents: didactic teaching versus electronic learning. Canad J Anesth 59: 852-860.

39. Teague G, Riley RH (2006) Online resuscitation training. Does it improve high school students' ability to perform cardiopulmonary resuscitation in a simulated environment? Resuscitation 71: 352-357.

40. Chung $\mathrm{CH}$, Axel YC, Lucia LK, Lam CY, Peter CY (2010) Comparing the effectiveness of video self-instruction versus traditional classroom instruction targeted at cardiopulmonary resuscitation skills for laypersons: a prospective randomised controlled trial. Hong Kong Med J 16(3): 165-70.

41. Semeraro F, Taggi F, Tammaro G, Imbriaco G, Marchetti L, et al. (2011) iCPR: a new application of high-quality cardiopulmonary resuscitation training. Resuscitation 82: 436-441. 